ISSN 0103-8478

\title{
Micropropagação de umburana de cheiro
}

\author{
Micropropagation of umburana de cheiro
}

\section{Vania Celene Alecrim Campos ${ }^{\mathrm{I}}$ Alone Lima-Brito ${ }^{\mathrm{II}}$ Ingrid Estefania Mancia de Gutierrez ${ }^{\mathrm{III}}$ José Raniere Ferreira de Santana ${ }^{\mathrm{IV}}$ Ana Valéria Vieira de Souza ${ }^{\mathrm{V}}$}

\section{RESUMO}

Umburana-de-cheiro é uma espécie nativa da Caatinga, amplamente utilizada pela população local, devido $o$ valor madeireiro, ornamental, forrageiro e, principalmente medicinal. Considerando o significativo risco de extinção e a inexistência de estudos relacionados ao cultivo e propagação, objetivou-se com este trabalho estabelecer um protocolo para micropropagação de Amburana cearensis. Para isso, avaliouse a influência do regulador vegetal 6-benzilaminopurina (BAP) em cinco concentrações $(0,0 ; 2,22 ; 4,44 ; 8,88$ e 17,76 $\mu \mathrm{M})$ sobre a multiplicação in vitro de diferentes explantes (segmento nodal, ápice caulinar e segmento cotiledonar) e na etapa de enraizamento testou-se diferentes concentrações de ácido indol butírico (AIB) $(0,0 ; 2,5 ; 5,0$ e 10,0 $\mu M)$ na presença e ausência de $1,0 \mathrm{~g}^{-1}$ de carvão ativado. Maior número de brotos $(2,36)$ foi obtido na presença de $4,44 \mu \mathrm{M}$ de BAP, a partir do segmento cotiledonar e maior porcentagem de enraizamento (92,0\%) ocorreu na presença de 10,0 $\mu \mathrm{M}$ de AIB na ausência de carvão ativado. Não existiram dificuldades para o estabelecimento do protocolo de micropropagação de A. cearensis.

Palavras-chave: Amburana cearensis, planta medicinal, extinção, organogênese.

\section{ABSTRACT}

Umburana de cheiro is a species native to the Caatinga, widely used by local people, because the value of timber, ornamental, forage and especially medicinal. Considering the significant risk of extinction and the ausence of studies related to the cultive and propagation, the aim of this work was to establish

\begin{abstract}
a protocol for micropropagation Amburana cearensis. For this, we evaluated the influence of plant growth regulator BAP at five different concentrations $(0.0,2.22,4.44,8.88$ and $17.76 \mathrm{mM})$ on the in vitro multiplication of different explants (nodal segments, apex cotyledon and stem segment) and the rooting stage we tested different concentrations of IBA $(0.0,2.5,5.0$ and $10.0 \mathrm{mM})$ in the presence and absence of $1.0 \mathrm{~g} L^{-1}$ of activated charcoal. Highest number of shoots (2.36) was obtained in $4.44 \mathrm{mM}$ of BAP from cotyledonary segment and higher rooting percentage (92.0\%) ocurred in 10.0mM of IBA in the absence of activated charcoal. There were no difficulties to the establishment of micropropagation protocol A. cearensis.
\end{abstract}

Key words: Amburana cearensis, medicinal plant, endangered, organogenesis.

\section{INTRODUÇÃO}

Amburana cearensis (Allem.) A. C. Smith, (Fabaceae), é uma espécie nativa da Caatinga, conhecida popularmente como amburana, amburana-de-cheiro, cumaru, cumaru-do-ceará, cumaru-das-caatingas, imburana, imburana-decheiro e umburana, utilizada de modo significativo pela população do semiárido, devido o valor madeireiro, ornamental, forrageiro e medicinal. As sementes e cascas do caule são amplamente

'Programa de Pós-graduação em Recursos Genéticos Vegetais, Universidade Estadual de Feira de Santana (UEFS), Feira de Santana, BA, Brasil.

"Programa de Pós-graduação em Botânica, UEFS, Feira de Santana, BA, Brasil.

IIIPrograma de Pós-graduação em Biotecnologia, UEFS, Feira de Santana, BA, Brasil.

${ }^{\text {IV }}$ Departamento de Biologia, UEFS, Feira de Santana, BA, Brasil.

${ }^{\vee}$ Embrapa Semiárido, Centro de Pesquisa Agropecuária do Trópico Semiárido (CPATSA), BR 482, Km 152, Zona Rural, CP 23, 56302-970, Petrolina, PE, Brasil. E-mail: ana.valeria@ cpatsa.embrapa.br. Autor para correspondência. 
utilizadas na medicina popular como medicação caseira no tratamento de bronquites, asma, gripes, resfriados e em casos de dores reumáticas (MAIA, 2006; LORENZI \& MATOS, 2008).

No entanto, toda a coleta da planta para as diversas finalidades de uso, ainda é realizada por meio do extrativismo, que atualmente pode ser classificado como predatório. A comercialização das sementes e cascas do caule pode ser observada com frequência, em feiras livres de diversos municípios localizados no semiárido nordestino, o que contribui para a redução de populações de ocorrência natural, uma vez que impede a propagação natural da espécie.

A relevância desses aspectos demonstra a necessidade urgente do estabelecimento de programas voltados à sua produção e conservação, assim como aumentam a necessidade de pesquisas com alternativas de propagação. Até o presente momento, não existem referências de pesquisas realizadas neste contexto para a Amburana cearensis.

A cultura de tecidos é uma técnica importante que pode ser utilizada para a produção de espécies nativas passíveis de extinção, uma vez que possibilita a rápida multiplicação a partir de um único indivíduo, em qualquer época do ano, com maior controle sobre a sanidade do material propagado (THAKUR \& KARNOSY, 2007).

Neste contexto, objetivou-se com este trabalho, estabelecer uma metodologia adequada para a micropropagação de $\boldsymbol{A}$. cearensis, a fim de viabilizar a produção de mudas em larga escala, que poderão ser replantadas no habitat de ocorrência natural amenizando o risco de erosão genética.

\section{MATERIAL E MÉTODOS}

Sementes de Amburana cearensis, obtidas de diferentes plantas matrizes, foram adquiridas em feiras livres do município de Euclides da Cunha, BA em 2008 e armazenadas em sacos de papel Kraft à temperatura ambiente, por um período de trinta dias. Para a assepsia, as sementes foram deixadas em água corrente por $10 \mathrm{~min}$, imersão em etanol a $70 \%$ - $1 \mathrm{~min}$, seguido de solução de hipoclorito de sódio $(2,5 \%$ de cloro ativo) com duas gotas de detergente neutro $15 \mathrm{~min}$. Posteriormente, foram enxaguadas em água destilada autoclavada e colocadas em tubos de ensaio (25x150mm), contendo $10 \mathrm{~mL}$ do meio de cultura Wood Plant medium (WPM) (LLOYD \& MCCOWN, 1980) suplementado com $100 \mathrm{mg} \mathrm{L}^{-1}$ de mio-inositol, $30 \mathrm{~g} \mathrm{~L}^{-1}$ de sacarose, $7 \mathrm{~g} \mathrm{~L}^{-1}$ de ágar (Himedia ${ }^{\circledR}$ ). $\mathrm{O} \mathrm{pH}$ foi ajustado para $5,7 \pm 0,1$ utilizando-se $\mathrm{NaOH}$ ou $\mathrm{HCl}$ $0,1 \mathrm{~N}$ antes da autoclavagem. Os tubos de ensaio foram tampados com tampa plástica e vedados com parafilme e mantidos em sala de crescimento com temperatura de $25 \pm 3^{\circ} \mathrm{C}$, fotoperíodo de 16 horas e radiação

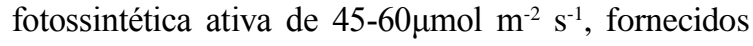
por lâmpadas do tipo fluorescente branca fria.

Para o experimento de multiplicação, foram utilizados o ápice caulinar (AC), o segmento nodal (SN) e o segmento cotiledonar (SC), retirados das plantas germinadas in vitro, com 45 dias. Os explantes foram colocados verticalmente em meio de cultura WPM suplementado com BAP em cinco concentrações $(0,0 ; 2,22 ; 4,44 ; 8,88$ e $17,76 \mu \mathrm{M})$.

$\mathrm{O}$ delineamento experimental utilizado foi inteiramente casualizado (DIC) em esquema fatorial $3 \times 5$ (três tipos de explante $\mathrm{x}$ cinco concentrações de BAP), totalizando 15 tratamentos com cinco repetições e cinco tubos por parcela. Aos 45 dias após a instalação do experimento, avaliou-se o número de brotos por explante, o comprimento da parte aérea $(\mathrm{cm})$, biomassa fresca e seca da parte aérea $(\mathrm{mg})$ e porcentagem de explantes com brotos (\%).

No experimento de enraizamento, foram utilizados brotos com um par de folhas $(\sim 2,0 \mathrm{~cm}$ de comprimento) provenientes do explante segmento cotiledonar, colocados em meio de cultura WPM suplementado com diferentes concentrações de AIB $(0,0 ; 2,5 ; 5,0$ e $10,0 \mu \mathrm{M})$ na presença ou ausência de $1,0 \mathrm{~g} \mathrm{~L}^{-1}$ de carvão ativado.

$\mathrm{O}$ experimento foi instalado em DIC em esquema fatorial 4x2 (quatro concentrações de AIB $\mathrm{x}$ presença ou ausência de carvão ativado), totalizando oito tratamentos, com cinco repetições e cinco tubos por parcela. Aos 30 dias após a instalação do experimento avaliou-se a porcentagem de brotos enraizados (\%), número de raízes por broto, comprimento das raízes $(\mathrm{cm})$, biomassa fresca e seca da raízes $(\mathrm{mg})$. Para a avaliação da biomassa fresca e seca nos dois experimentos (multiplicação e enraizamento), o material fresco foi pesado em balança analítica e posteriormente colocado em estufa com circulação de ar forçado, na temperatura de $40^{\circ} \mathrm{C}$ até obtenção do peso constante, para avaliação do peso seco.

As plantas enraizadas in vitro com trinta dias, foram transferidas para copos plásticos de $500 \mathrm{~mL}$, contendo uma mistura de terra vegetal e vermiculita $\left(1: 1 \mathrm{v} \mathrm{v}^{-1}\right)$, mantidas em casa de vegetação a $70 \%$ de luminosidade, com temperatura e umidade relativa ambiente. Cada planta foi protegida com uma garrafa plástica tipo pet. As tampas das garrafas foram desenroscadas no $2^{\circ}$ dia e retiradas no $5^{\circ}$ dia. No $10^{\circ}$ dia de transplantio, as garrafas foram removidas. Aos 30 e 60 dias da transferência avaliouse a porcentagem de sobrevivência das plantas. 
Para a análise estatística dos experimentos, os dados foram submetidos à análise de variância, sendo os dados quantitativos avaliados por regressão no software estatístico SISVAR (FERREIRA, 2011).

\section{RESULTADOS E DISCUSSÃO}

Todas as variáveis analisadas apresentaram distribuição normal e, no experimento de multiplicação, a análise de variância demonstrou efeito altamente significativo $(\mathrm{P} \leq 0,01)$ da interação dupla para todas as variáveis observadas, enquanto que para a porcentagem de explantes responsivos $o$ efeito foi significativo $(\mathrm{P} \leq 0,05)$. Para o explante segmento nodal, observou-se uma tendência no aumento do número de brotos em meio suplementado com o BAP até a concentração 4,44 $\mu \mathrm{M}(1,24)$. Para o ápice caulinar, o maior número de brotos $(1,2)$ foi obtido em meio WPM suplementado com 2,22 $\mu \mathrm{M}$ de BAP e para o explante segmento cotiledonar na presença de $4,44 \mu \mathrm{M}$ de BAP, foi possível obter 2,36 brotos por explante (Figura 1A). Mesmo que este valor não seja o desejável em protocolos de micropropagação, avanços foram obtidos, o que é relevante considerando o risco de extinção da espécie.

Os resultados obtidos neste trabalho em relação aos explantes testados, corroboram com aqueles encontrados para a copaíba (Copaifera langsdorfii) (NOLETO \& SILVEIRA, 2004) e urucum (Bixa orellana) (CARVALHO et al., 2005), em que a proliferação de brotos a partir de segmentos cotiledonares também apresentou os melhores resultados quando comparado a outros tipos de explantes.

Diferentemente deste trabalho com a umburana, a maior parte das pesquisas para o estabelecimento de protocolos de micropropagação, têm sido realizada utilizando-se o segmento nodal para a multiplicação (SOUZAet al., 2004; SANTANA et al., 2011; SOUZA et al., 2011). SOUZA et al. (2011), comentam que dentre os tipos de explantes mais utilizados, as gemas apicais e axilares e os segmentos nodais, promovem clones true-to-type, ou seja, idênticos à planta matriz e por isso são os mais indicados para a multiplicação e conservação in vitro
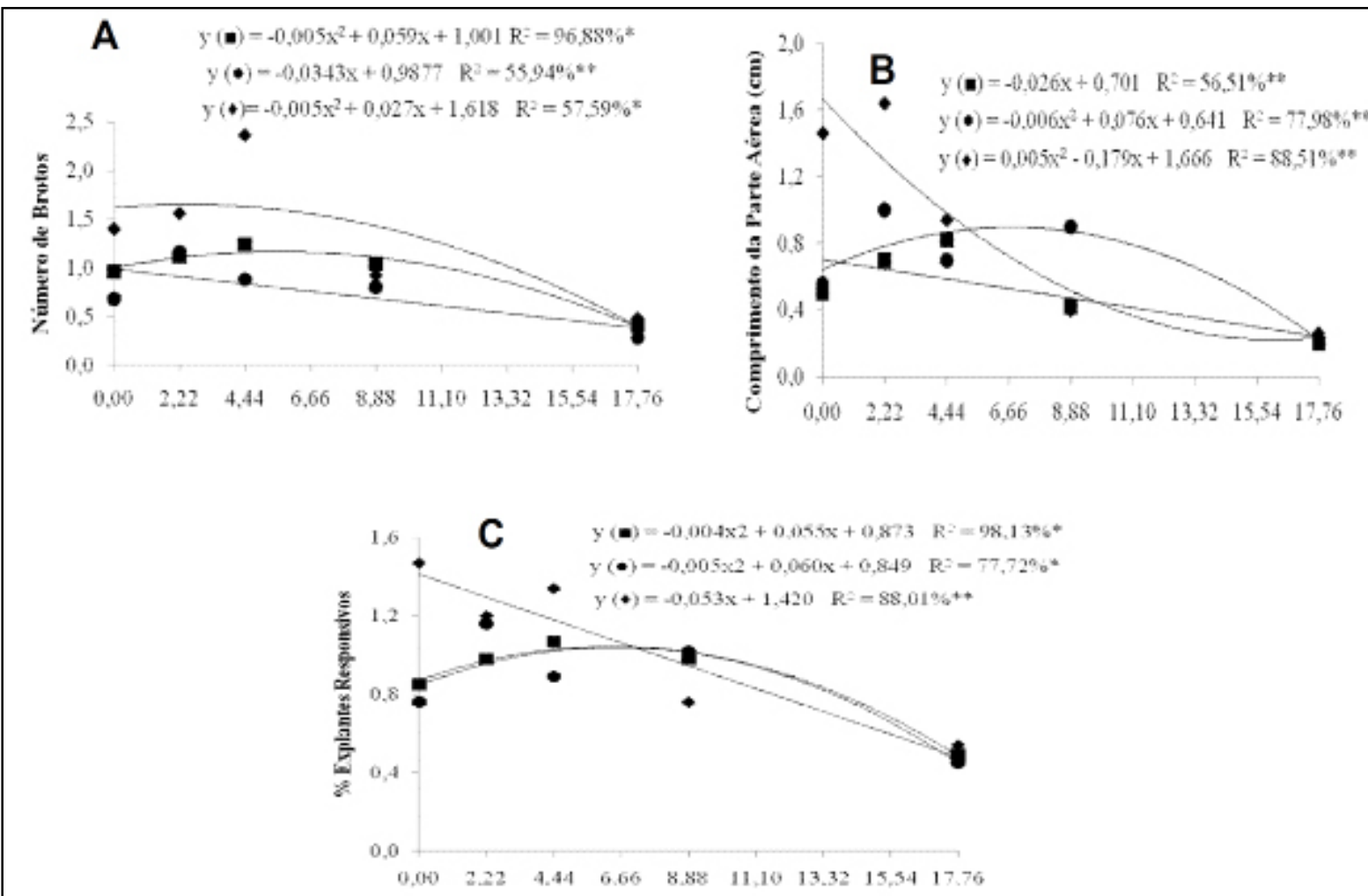

Figura 1 - (A) Número de brotos, (B) comprimento da parte aérea $(\mathrm{cm})$ e (C) porcentagem de explantes responsivos dos brotos oriundos

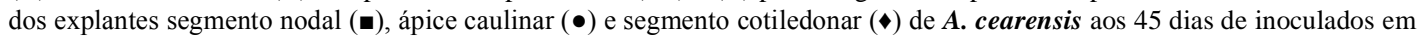
meio WPM suplementados com diferentes concentrações de BAP $(\mu \mathrm{M})(* \mathrm{P} \leq 0,05$ e ** $\mathrm{P} \leq 0,01$ pelo teste $\mathrm{F})$. 
de genótipos elites. Contudo, cada resposta depende da espécie estudada.

Em relação à concentração de $4,44 \mu \mathrm{M}$ de BAP resultados semelhantes também foram reportados para outras espécies com potencial terapêutico, como a fruta do macaco (Feronia limonia) (HIREGOUDAR et al., 2003) e a framboesa (Rubus idaeus) (VILLA et al., 2006). Mas para outras espécies medicinais, como o urucum (Bixa orellana) (CARVALHO et al., 2005), canjerana (Cabralea canjerana) (ROCHA et al., 2007) e peroba rosa (Aspidosperma polyneuron) (RIBAS et al., 2005), os autores observaram que o maior número de brotos foi obtido em concentrações diferentes de $4,44 \mu \mathrm{M}$ de BAP. Esta variação de resultados, está de acordo com CALDAS et al. (1998), quando sugerem que a concentração dos reguladores vegetais no meio de cultura são fatores determinantes no crescimento e no padrão de desenvolvimento na maioria dos sistemas de cultura de tecidos.

Contudo, além da ação direta dos reguladores vegetais nas diferentes etapas de um protocolo de micropropagação, o crescimento e desenvolvimento de plantas cultivadas em condições in vitro, ainda é um processo complexo que envolve fatores endógenos e exógenos não completamente elucidados. O genótipo, a nutrição mineral, condições inerentes à planta matriz, concentrações endógenas de hormônios, dentre outros fatores, também podem interferi no processo. Desse modo, cada protocolo deve ser estabelecido considerando-se, principalmente, a espécie de interesse.

Para o comprimento das brotações, o aumento da concentração desta citocinina foi prejudiciale maior valor médio $(1,64 \mathrm{~cm})$ foi observado

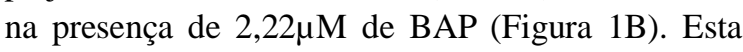
resposta já poderia ser esperada, considerando que o BAP, em excessivas concentrações, pode causar toxicidade e prejudicar o crescimento de brotações induzidas in vitro. Resultados similares foram reportados para a arnica da serra (Lychnophora pinaster) (SOUZA et al., 2004) e a framboesa (Rubus idaeus) (VILLA et al., 2006). Segundo GRATTAPAGLIA \& MACHADO (1998), as citocininas utilizadas durante a multiplicação in vitro promovem formação de parte aéreas, mas seu excesso pode ser tóxico e levar ao encurtamento dos entrenós, principalmente o BAP.

Para a variável matéria seca da parte aérea, o maior incremento para o explante ápice caulinar (5,78mg), ocorreu em meio acrescido de $2,22 \mu \mathrm{M}$ de BAP e para o segmento cotiledonar, o maior valor (5,46mg) foi obtido na ausência de BAP (dados não mostrados).

A maior porcentagem de explantes responsivos ocorreu em meio suplementado com 4,44 e $2,22 \mu \mathrm{M}$ de BAP, para segmento nodal $(68,0 \%)$ e ápice caulinar $(76,0 \%)$, respectivamente. Para o explante segmento cotiledonar, verificouse modelo matemático linear decrescente, sendo a melhor competência do explante $(96,0 \%)$ observada na ausência do BAP (Figura 1C). Esses resultados diferem daqueles obtidos por KIELSE et al. (2009), uma vez que os autores obtiveram $98,75 \%$ de resposta do segmento cotiledonar cultivado em meio de cultura suplementado com BAP.

$\mathrm{Na}$ etapa de enraizamento, maior porcentagem de brotos enraizados $(92,0 \%)$ foi observado na presença de 10,0 $\mu \mathrm{M}$ de AIB e ausência de carvão ativado (Figura 2A). Na mesma condição, foram obtidos os resultados mais eficientes para matéria seca $(17,32 \mathrm{mg})$, comprimento $(2,28 \mathrm{~cm})$ e número de raízes $(3,12)$ (Figura 2B e 2C).

Segundo GRATTAPAGLIA \& MACHADO (1998), os efeitos benéficos do carvão ativado podem ser físico, uma vez que simula uma condição de escuro mais favorável ao desenvolvimento de raízes adventícias, como também, químico adsorvendo substâncias prejudiciais ao enraizamento, como os compostos fenólicos. Entretanto, pode também adsorver auxinas e nutrientes do meio, necessários ao enraizamento e desenvolvimento normal da parte aérea.

Para ASSIS \& TEIXEIRA (1999), espécies lenhosas, em geral, são beneficiadas com o uso de carvão ativado. Contudo, esta substância possui alta capacidade de adsorção e pode reter parte dos elementos que compõem o meio de cultura, inclusive substâncias promotoras do enraizamento, o que pode ter ocorrido neste experimento com a espécie Amburana cearensis.

Assim como neste estudo, em culturas de pereira (Pyrus serotina) (ERIG et al., 2004), pequi (Caryocar brasiliense) (SANTOS et al., 2006) e jenipapo (Genipa americana) (ROCHA et al., 2008), que também apresentam propriedades terapêuticas, a presença de carvão ativado não favoreceu a indução de raízes in vitro. De acordo com MCCOWN (1988), o efeito do carvão in vitro depende da composição química do meio, mas também do genótipo da planta.

Durante a aclimatização, houve $40 \%$ de sobrevivência das plantas, após sessenta dias da transferência para o substrato. Estes resultados são semelhantes aos encontrados para outras espécies lenhosas como angico (Parapiptadenia rigida) 


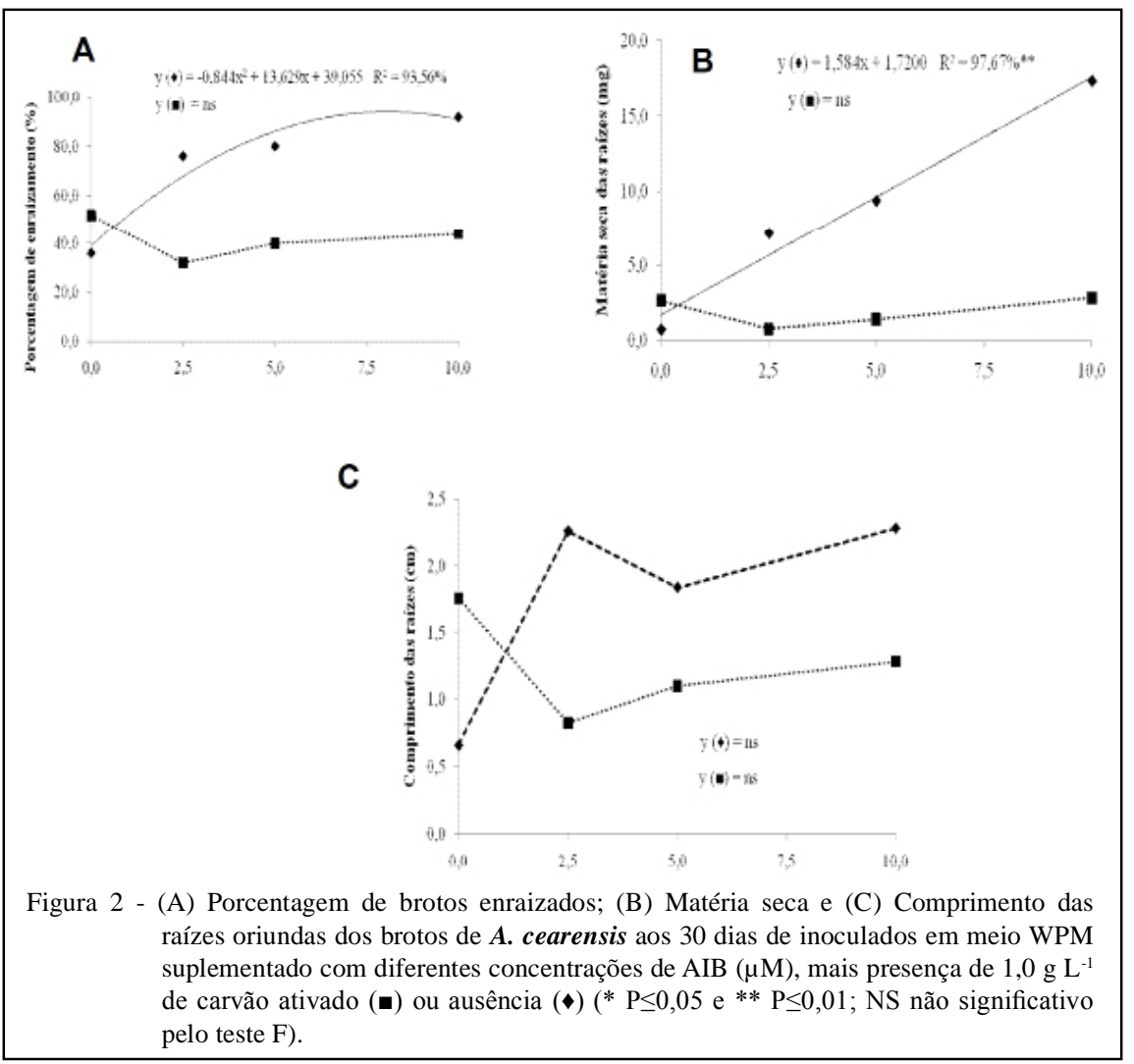

(KIELSE et al., 2009) e barbatimão (Stryphnodendren adstringens) (NICIOLI et al., 2008), em que taxas de aclimatização abaixo de 50\% também foram relatadas.

Diversos fatores podem contribuir para o insucesso no processo de aclimatização como as condições ambientais, condições de cultivo e manutenção em casa de vegetação, além das condições funcionais dos tecidos vegetais formados em condições de laboratório. Mesmo que o número de mudas de A. cearensis obtidas em condições in vitro, tenha sido menor que $50 \%$, os resultados apresentados anteriormente, mostraram que não existiram dificuldades para o estabelecimento do protocolo de micropropagação da espécie.

\section{CONCLUSÃO}

A micropropagação de $\boldsymbol{A}$. cearensis foi favorecida com a utilização do explante segmento cotiledonar em baixas concentrações de BAP. Na etapa do enraizamento, a presença do AIB favoreceu a emissão de raízes, porém o carvão ativado não foi benéfico. O processo de aclimatização das mudas de A. cearensis não foi eficiente nas condições testadas.

\section{REFERÊNCIAS}

CALDAS, L.S. et al. Meios nutritivos. In: TORRES, A.C. et al. Cultura de tecidos e transformação genética de plantas. Brasília: Embrapa-SPI/Embrapa-CNPH, 1998. p.87-132.

CARVALHO, J.F.P. et al. Regeneração in vitro de urucum (Bixa orellana L.) a partir de diferentes tipos de explantes. Revista Árvore, v.29, n.6, p.887-895, 2005. Disponível em: <http://www.scielo.br/scielo.php?script=sci_arttext\&pid $=$ S0100-67622005000600007>. Acesso em: 03 fev. 2012. doi: doi. org/10.1590/S0100-67622005000600007.

ERIG, A.C. et al. Enraizamento in vitro e aclimatização de mudas de marmeleiro cvs. 'Mc' e 'Adams', utilizadas como portaenxerto para pereira. Scientia Agraria, v.5, n.12, p.61-68, 2004. Disponível em: <http://www.sumarios.org/sites/default/files/ pdfs/469_1999.pdf>. Acesso em: 25 nov. 2010.

FERREIRA, D.F. Sisvar: a computer statistical analysis system. Ciência e Agrotecnologia, v.35, p.1039-1042, 2011. Disponível em: <http://www.scielo.br/scielo.php?pid=S1413$70542011000600001 \&$ script $=$ sci_arttext $>$. Acesso em: 26 abr. 2012. doi: doi.org/10.1590/S1413-70542011000600001.

GRATTAPAGLIA, D.; MACHADO, M.A. Micropropagação. In: TORRES, A.C. et al. Cultura de tecidos e transformação genética de plantas. Brasília: EMBRAPA, 1998. p.183-260.

HIREGOUDAR, L.V. et al. Multiple shoot induction and plant regeneration of Feronia limonia (L.) Swingle. Scientia 
Horticulturae, v.98, p.357-364, 2003. Disponível em: <http://www. sciencedirect.com/science/article/pii/S0304423803000189>. Acesso em: 03 mar. 2012. doi: doi.org/10.1016/S0304-4238(03)00018-9.

KIELSE, P. et al. Regeneração in vitro de Parapiptadenia rigida. Ciência Rural, v.39, n.4, p.1088-1094, 2009. Disponível em: <http://www.scielo.br/scielo.php?script=sci_arttext\&pid= S0103-84782009000400020>. Acesso em: 23 jul. 2010. doi: doi. org/10.1590/S0103-84782009005000046.

LLOYD, G.; McCOWN, B. Use of microculture for production and improvement of Rhododendron spp. HortScience, Alexandria, v.15, p.415, 1980. (Abst. 321).

LORENZI, H.; MATOS, F.J.A. Plantas medicinais no Brasil: nativas e exóticas. 2.ed. Nova Odessa: Instituto Plantarum, 2008. 544p.

MAIA, G.N. Caatinga: árvores e arbustos e suas utilidades. São Paulo: D e Z computação, 2006. p.104-114.

McCOWN, B.H. Adventitious rooting of tissue cultured plants. In: DAVIS, T.D. et al. Adventitious root formation in cuttings. Portland: Dioscorides, 1988. V.2, p.289-302.

NICIOLI, P.M. et al. Ajuste no processo de micropropagação do barbatimão. Ciência Rural, v.38, n.3, p.685-689, 2008. Disponível em: <http://www.scielo.br/scielo.php?script=sci_arttex t\&pid=S0103-84782008000300014>. Acesso em: 23 maio, 2010. doi: doi.org/10.1590/S0103-84782008000300014.

NOLETO, L.G.; SILVEIRA, C.E.S. Micropropagação de copaíba. Biotecnologia Ciência e Desenvolvimento, v.33, p.109-120, 2004. Disponível em: <http://www.biotecnologia.com.br/revista/ bio33/copaiba.pdf>. Acesso em: 05 dez. 2010.

RIBAS, L.L.F. et al. Micropropagação de Aspidosperma polyneuron (peroba-rosa) a partir de segmentos nodais de mudas juvenis. Revista Árvore, v.29, n.4, p.517-524, 2005. Disponível em: <http://www.scielo.br/scielo.php?script=sci_arttext\&pid= S0100-67622005000400003>. Acesso em: 23 maio, 2011. doi: doi.org/10.1590/S0100-67622005000400003.

ROCHA, M.A.C. da et al. Enraizamento in vitro e aclimatização de genótipos de jenipapeiro (Genipa americana L.). Revista Brasileira de Fruticultura, v.30, n.3, p.769-774, 2008.
Disponível em: <http://www.scielo.br/scielo.php?script=sci_artte xt\&pid=S0100-29452008000300035 >. Acesso em: $11 \mathrm{dez} 2011$. doi: doi.org/10.1590/S0100-29452008000300035.

ROCHA, S.C. et al. Micropropagação de Cabralea canjerana. Revista Árvore, v.31, n.1, p.43-50, 2007. Disponível em: <http://www.scielo.br/scielo.php?pid=S010067622007000100006\&script=sci_arttext $>$. Acesso em: $15 \mathrm{dez}$. 2011. doi: doi.org/10.1590/S0100-67622007000100006.

SANTANA, J.R.F. et al. Efeito da fonte de carbono na multiplicação in vitro de Annona sp. Ciência e Agrotecnologia, v.35, n.3, p.487-493, 2011. Disponível em: <http://www.scielo. br/scielo.php?pid=S1413-70542011000300008\& script $=$ sci $_{-}$ arttext>. Acesso em: 03 jun. 2012. doi: doi.org/10.1590/S141370542011005000002 .

SANTOS, B.R. et al. Micropropagação de pequizeiro (Caryocar brasilliense Cam.). Revista Brasileira de Fruticultura, v.28, n.2, p.293-296, 2006. Disponível em: <http://www.scielo. br/scielo.php? pid=S0100-29452006000200031\&script $=$ sci $_{-}$ arttext>. Acesso em: 15 jul. 2011. doi: doi.org/10.1590/S010029452006000200031.

SOUZA, A.V. et al. Germinação de embriões e multiplicação in vitro de Lychnophora pinaster Mart. Ciência \& Agrotecnologia, Ed. Esp, p.1532-1538, 2003. Disponível em: <sumarios.org/sites/ default/files/pdfs/36197_4551.PDF>. Acesso em: 03 jun. 2012.

SOUZA, A.V. et al. Micropropagação de Dioscorea multiflora Grised. Ciência e Agrotecnologia, v.35, n.1, p.92-98, 2011. Disponível em: <http://www.scielo.br/scielo.php?script=sci_artte xt\&pid=S1413-70542011000100011 >. Acesso em: 02 jun. 2012. doi: doi.org/10.1590/S1413-70542011000100011.

THAKUR, R.C.; KARNOSKY, D.F. Micropropagation and germoplasma conservation of Central Park Splendor Chinese elm (Ulmus parvifolia) Jacq. 'A/Ross Central Park') trees. Plant Cell Reports, v.26, p.1171-1177, 2007. Disponível em: <http://cat. inist.fr/?aModele $=$ afficheN\&cpsidt $=18952723>$. Acesso em: 23 out. 2011.

VILLA, F. et al. Multiplicação in vitro de amoreira-preta cultivar 'Brazos'. Ciência \& Agrotecnologia, v.30, n.2, p.266-270, 2006. Disponível em: <http://www.scielo.br/pdf/cagro/v30n2/v30n2a11. pdf $>$. Acesso em: 12 jun. 2011. 